BY JEFFREY CASDIN

\title{
TAKING STOCK
}

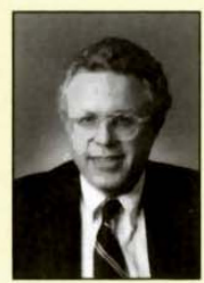

Periodically, it's helpful to review our investment thesisfor biotechnology, making reassessments in light of recent developments and those expected in the near future. This seems to be an appropriate time for such a reassessment, given the dreadful losses many biotech investors are saddled with and the feeling of many that it will take a long time just to get even, never mind make a profit.

Our thesis is that biotechnology — which has expanded in scope to include lasers and massive computing power, as well as genes, antibodies, and other technologies-has improved the return on capital of drug development to the point where start-up companies can now break into the drug business, a feat that had previously been nearly impossible. Biotechnology has provided a blueprint for understanding the way biological mechanisms work at the molecular level, leading to the development of new drugs that address disease more specifically. This specificity permits a drug to achieve potent efficacy, while limiting toxicity in the rest of the body. Put another way, drugs with increasingly high therapeutic indexes (efficacy-to-safety ratios) are being developed. This trend has two financial implications. Capital investment per successful drug is dropping, because the success rate for approval by the Food and Drug Administration (FDA, Bethesda, MD) has risen significantly for these high therapeutic-index drugs. And the payback on this investment is more rapid, because they are opening up untapped, high-need markets. The technology holds the potential of successfully treating debilitating diseases like rheumatoid arthritis, as well as fatal diseases like cancer, and at far less cost than the mostly palliative therapies used today.

\section{Rapid advancements}

A corollary to our thesis is that the technology is advancing so rapidly that the few experts on the leading edge, whether in academia or industry, will continue to be attracted to these start-up companies and new drug companies where the lack of bureaucracy and a premium on achievement allow for the practical realization of their ideas and knowledge. Thus, the technological momentum in the biotechnology industry should persist as the field continues to draw the brightest minds in the world. In turn, this should continue to cause the large drug companies, rich in cash but poor in exciting new products, to enter into strategic alliances with and make acquisitions of biotech companies, providing a substantial portion of the equity needed by the smaller companies to keep product development rolling.

Over the past year or so, biotechnology has been advancing rapidly along the continuum from the essentially serendipitous discoveries of the old days to the rational design of drugs of the future, as discussed above. The marriage of cellreceptor isolation, compound chemistry, and computer/laser-controlled robotics technologies is giving rise to the ability to create and screen hundreds of millions of compounds, and find those few with high therapeutic indexes in only months rather than the years or decades it took previously. Advanced receptor-cloning techniques are producing an increasing number of targets to screen, and massively parallel-computing technology is giving the scientists in small companies the capability to actually view these receptors with bound drug candidates in order to optimize their activity. The scientists's ability to mediate the activity of a cell in the extracellular space is increasing exponentially. At the same time, the technology to delve into the intracellular space is developing at least as rapidly, potentially providing even more potent remedies for certain diseases because of the ability to inhibit with one compound the common pathological consequence of many extracellular events. Gene therapy, anti-sense/code blocking, and signal transduction technologies are examples of the intracellular approach.

Nearly as important, but often unnoticed, is the rapid advancement of technology to test the therapeutic indexes of these experimental drugs in human-like biological settings to more accurately predict their safetyand efficacy. Examples of this include living-cell based assays and transgenic animals with human immune systems and disease conditions.

\section{Empirical proof}

We believe this investment thesis has been empirically proven by the stunning success of Amgen (Thousand Oaks, CA), as well as the achievements at Genentech (S. San Francisco, CA), Chiron (Emeryville, CA), Genzyme (Cambridge, $\mathrm{MA}$ ), and Biogen (Cambridge, MA). The corollary to this thesis is more difficult to back up objectively, but subjectively, despite the current market environment, it appears that the pace of new start-ups is as high as ever and the steady migration of talent from the large drug companies to the large biotech companies to the small start-ups continues unabated. And, while the fruits of the rapid advancement of technologyalong the continuum toward rational drug design remain to be harvested, developments at the host of newly public biotech companies and some more established ones leave little doubt that they are ripening rapidly. Some of these categories and representative public companies include:

-High-volume receptor screening with novel compounds-Chiron and Affymax (Palo Alto, CA).

-Rational drug design-Biogen,

\section{ocenowiri

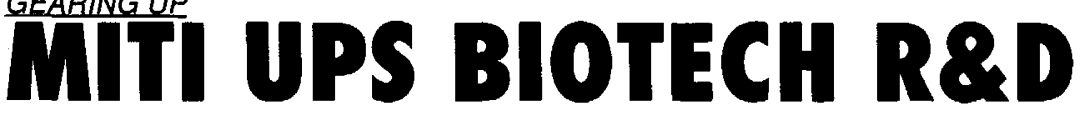

TOKYO-The powerful Ministry of International Trade and Industry (MITI) recently announced several new biotechnology-based programs involving a wide range of chemical and pharmaceutical companies, who share the projects's costs, contribute researchers and facilities, and-significantly, from the standpoint of international competition-get to commercialize the research results.

One of the key institutions through which MITI promotes the development of environmental conservation technologies is the Research Institute of Innova- tive Technology for the Earth (RITE), established in 1990. One RITE projectbegun when the institute opened and budgeted to date at roughly $\$ 560,000$ per year-is concerned with the development of high-performance bioreactor technology for the production of biochemicals. The bioreactors utilize the synthetic capacity of cellular reactions that occur under ambient temperature and pressure conditions. In this project, genes isolated from the energy-supply- 
Agouron Pharmaceuticals (LaJolla, CA), Vertex Pharmaceuticals (Cambridge, MA), and Protein Design Labs (Mountain View, CA).

-Gene therapy-Genzyme, Somatix (Cambridge, MA), and Genetic Therapy (Gaithersburg, MD).

-Anti-sense-Amgen, Gilead Sciences (Foster City, CA), Isis Pharmaceuticals (Carlsbad, CA), and Genta (San Diego, CA).

-Preclinical testing-DNX (Princeton, NJ), TSI (Worchester, MA), Advanced Tissue Sciences (La Jolla, CA), and Systemix (Palo Alto, CA).

\section{Strong reassertion}

Logic and evidence, therefore, suggest that biotech eventually will reassert itself on Wall Street even more strongly than it did last year, as hard as that might be to believe at this subdued moment. So for investors sitting on big losses or waiting to plunge back in, the next question is when? A better question in our mind is: Are the stocks cheap here? We prefer thisquestion because, when biotech stock prices do begin to climb, the move off the bottom will likely be so big that it should justify the wait as long as purchases are made at levels well below modestly bullish market valuations. The reader may recall that we thought the bigger biotech stocks had formed a hard bottom when Centocor (Malvern, PA) tanked in April and would successfully test their lows in an overall market correction that was bound to occur as the market sensed a bottom in the interestrate decline (Bio/Technology10:738, July '92). But we felt that many smaller stocks, particularly the initial public offerings (IPOs) of 1991-1992, would probably bump along an eroding bottom in this correction as institutions continued to prune portfolios, individual investors took tax losses to offset blue-chip gains, and companies's cash burn eroded book value. It looks as if we are in the midst of this process now, and we expect it to taper off before the year is out.

That's a subjective, technical analysis. In order to determine whether these small stocks are fundamentally cheap, one must have an opinion on the value of the underlying technology and intellectual-property assets each company possesses. While there would certainly be a wide range of values that experts in the field would arrive at when valuing these companies, there comes a point when biotech experts would find that almost all their valuations are above public-market levels. We think we are close to that point. We find the value for several recent IPOs that the market is placing on their technology and product pipelines (market capitalization less cash) is now close to or below the value placed on these companies during their last round of private financing. Buyers at that time were usually venture-capital experts not in the habit of overpaying, who had less of a track record to go on than we have now, and whose investments inherently contained more risk because they had no liquidity to get out. In a couple of cases, these investors have reaffirmed theirvaluation decisions and have bought more stock in the public market. When these kinds of valuations and events are seen in a number of cases, it doesn't take a genius to figure out that a bottom in fundamental valuations is very near.

\section{Within a year}

Now we'll take a stab at answering the "when" question. Since Amgen's emergence in the spring of last year was the catalyst for the subsequent huge rise in biotech stocks, one might look into the crystal ball to see if history will repeat itself. While we think an Amgen is a oncein-a-generation type occurrence, we do believe there is a possibility that a group of stocks in concert will have an emerging Amgen-type effect on the overall biotech market.

There are certainly enough products in advanced clinical trials or before the FDA to do the trick, probably within the next 12 months. Centocor could rise from the ashes with an HA-1A approval and take off again with potentially positive phase-III data in mid-1993 on its anticoagulant CentoRx. Synergen (Boulder,
CO) could publish phase-III data on its Antril product around the same time that would make FDA approval practically moot. Chiron could pop an approval for beta interferon in multiple sclerosis before the end of 1993 that could boost earnings projections dramatically. Biogen could publish some phase-II data on its slightly different version of beta interferon in hepatitis, showing improved efficacy in certain important subgroups and superior safety results compared to alpha interferon, presently a \$500-million product. Immunex (Seattle, WA), with three potential blockbustersin trials (PIXY-321 and two soluble réceptors), also could pull a big one out of the hat with data next year. These are some of the big fireworks that in concert could light up the sky. But there are also dozens of smaller, newer companiesfrom the second tier, and the 60 IPOs of 19911992 could set off a shower of clinicaltrial fireworks during the same period.

One final, critical development that should help reduce the anxiety of a closed financing window and make a rally in biotech more broadly based is the fix that many of the established drug companies find themselves in. Earnings growth through price increases, a fixture of the past few years, is over as the government and managed-care companiesconsolidate buying power over drugs, forcing purchasing of the cheapest product in a class. This is intensifying the drive to find new, one-in-a-class innovative drugs that can command proprietary pricing and to find these drugs soon to rescue obviously faltering earnings growth. Where else can the drug companies turn but to biotechnology? That's our investment thesis at work again. Eli Lilly (Indianapolis, IN) gave Centocor $\$ 100$ million and paid twice the market price for its stock for a share of HA-1A. Moreover, there's plenty more cash from where that came. Look for more big deals at prices well above market levels and for the market to start responding to the fundamental values they reveal.

Jeffrey Casdin is managing director at Oppenheimer (New York). ing systems of useful microorganisms are modified to optimize the production of cellulites and other desired substances.

The three newest projects, for which funding has just been requested, show the increasing importance of DNA research. They include a project to apply genetic engineering to environmental monitoring, with a first-year request of $\$ 192,000$. Typically, initial funding is lower than the levels in succeeding years. A second project involves sequencing
DNA at high rates with high accuracy, with an initial request of $\$ 328,000$. The third project focuses on developing computer software to process "genetic information,"including DNA sequencing and homology testing. The first-year request is $\$ 304,000$.

In the DNA sequencing project, Hideatsu Maeda, research scientist at the Research Institute for Polymers and Textiles (Tsukuba), says that the project will study carbon dioxide fixation by microorganisms.

In terms of computerization, says Masaaki Yamamoto, assistant director of MITI's Biochemical Industry Division, "there is currentlylittle information technology concerned with biotechnology in Japan." That could change. The project will use a 1000-processing-element parallel-processing computer developed as a result of MITI's recently concluded Fifth Generation Computer Project.

-Stuart M. Dambrot 